\title{
Association between OGG1 Ser326Cys polymorphism and risk of upper aero-digestive tract and gastrointestinal cancers: a meta-analysis
}

\author{
Sambuddha Das, Sayantan Nath, Aditi Bhowmik, Sankar Kumar Ghosh and Yashmin Choudhury*
}

\begin{abstract}
Cancers of the upper aero-digestive and gastrointestinal tract are one of the major causes of mortality around the world. DNA repair genes play a vital role in preventing carcinogenesis by maintaining genomic integrity. Polymorphisms in the nucleotide sequence of DNA repair genes are often reported to be associated with an increased risk for different cancers. The OGG1 gene encodes the enzyme 8-oxoguanine DNA glycosylase which removes oxidatively damaged bases of DNA. Several studies report that the OGG1 Ser326Cys polymorphism increases the risk for cancers of the upper aero-digestive and gastrointestinal tract. However, other studies provide evidence that such an association does not exist. A meta-analysis to assess the role of OGG1 Ser326Cys polymorphism in the cancers of the upper aero-digestive and gastrointestinal tract was therefore undertaken in order to resolve this ambiguity. Seventeen studies were recruited for this meta-analysis after screening 58 articles with a total of 5533 cases and 6834 controls for which the odds ratio with $95 \%$ confidence interval was calculated. Begg's funnel test and Egger's test were performed for calculating publication bias. Our study reveals an association between OGG1 Ser326Cys polymorphism and cancer susceptibility of the upper aero-digestive and gastrointestinal tract (CG + GG vs CC; odds ratio, OR 1.22; $95 \%$ Cl 1.05-1.41; GG vs CG + CC; OR 1.36; 95 \% Cl 1.09-1.70; GG vs CC; OR 1.46; 95 \% Cl 1.12-1.92). Subgroup analysis based on cancer types and ethnicity also revealed the association of OGG1 Ser326Cys polymorphism to the risk for upper aero-digestive and gastrointestinal tract cancers among both the Asian and the Caucasian populations. No risk was however observed for smoking habits and OGG1 Ser326Cys polymorphism. In conclusion, OGG1 Ser326Cys polymorphism may be associated with the increased risk for aero-digestive tract and gastro-intestinal cancers in both Asian and Caucasian populations.
\end{abstract}

Keywords: Gastrointestinal, Meta-analysis, OGG1, Upper aero-digestive tract

\section{Background}

Cancer is a multifarious disease characterised by abrupt growth of cells resulting in abnormal regulation of cellcycle progression and division (Sawyers 2004). The upper aero-digestive tract (UADT) cancers, comprising cancers of the oral cavity, pharynx, larynx and esophagus, are amongst the most common cancers globally, accounting for nearly 1 million new cases and 700,000 deaths each year (Babron et al. 2014). Gastrointestinal tract (GI)

*Correspondence: yashminchoudhury@gmail.com

Department of Biotechnology, Assam University, Silchar 788011, India cancers which encompasses the cancers in the digestive system including gastric cancer, colorectal cancer, esophageal cancer and pancreatic cancer present an interesting pattern in distribution over the world with major occurrences in Asia (Pourhoseingholi et al. 2015). Both genetic and environmental factors contribute to the onset of cancer (Bhowmik et al. 2015). Most cancers primarily involve the dysregulation of three classes of genes viz., (proto) oncogenes, tumor suppressor genes and DNA repair genes. Such dysregulation collectively contribute to the development of cancer genotype and phenotype, which resists the natural and inherent death mechanism(s) 
embedded in cells (apoptosis and like processes), coupled with impairment of cell proliferation events (Bhatt et al. 2010).

DNA damage is a major perpetrator of cancer, occurring by various mechanisms, including the effect of free radicals generated through endogenous cellular metabolism or the exposure to exogenous toxins such as environmental mutagens and many carcinogens (Hoeijmakers 2009; Zhou et al. 2015). Specific genes of some important pathways such as base excision repair (BER), mismatch repair (MMR), nucleotide excision repair (NER) and double-strand break repair (DSBR) may counteract damage to DNA, thereby maintaining genomic integrity and preventing carcinogenesis (Sedelnikova et al. 2010) Oxidation of guanine, adenine and thymine accounts for the most important damage to DNA (Zhou et al. 2015). The 7,8-dihydro-8-oxoguanine (8-oxoG) is the most recurrent DNA modification generated by the oxidation of guanine leading to mispairing with cytosine and adenine during DNA replication, thereby accumulating GC to TA mutations (Bravard et al. 2009). Tobacco smoke contains various carcinogens among which benzo[a]pyrene induces 8-oxoG formation in animal tissue. Increased levels of 8-oxoG have been reported in the lung DNA of smokers in comparison to those of non-smokers, indicating a clear correlation with tobacco related carcinogenesis. A $50 \%$ increase of 8-oxoG has also been reported in the urine of smokers compared to that of non-smokers. Studies have also found that aqueous smoke solutions can lead to the formation of superoxides and hydroxyl radicals. Together the tobacco smoke and its aqueous solution can lead to various aerodigestive and upperdigestive tract cancers (Elahi et al. 2002). The human 8-oxoguanine DNA glycosylase (OGG1), encoded by the OGG1 gene localized on chromosome 3p25 has both DNA glycosylase and apurinic or apyrimidinic (AP) lyase activities. It removes the 8-oxoG lesion by slicing the glycosydic bond between the modified base and the sugar moiety, leaving an abasic apurinic/apyrimidinic (AP) site in DNA (Zhou et al. 2015).

There are at least 20 validated sequence variants of OGG1 gene, of which the most studied functional polymorphism is an amino acid substitution of serine (Ser) with cysteine (Cys) (Ser326Cys) resulting from a C to $\mathrm{G}$ transversion at position 1245 in exon 7 of the OGG1 gene (Bravard et al. 2009). Numerous studies pertaining to the association of this polymorphism with the increased risk for several cancers have been performed. In most of these studies the Ser326Cys polymorphism was found to increase the risk for different cancers such as head and neck cancer, colorectal cancer and gall bladder cancer (Kumar et al. 2011; Canbay et al. 2011; Srivastava et al. 2009), in association with etiological habits such as smoking (Elahi et al. 2002). However, some recent studies have also reported no association of Ser326Cys polymorphism with the increased risk for cancer (Gorgens et al. 2007; Laantri et al. 2011; Sameer et al. 2012). It has also been reported that individuals with the homozygous recessive allele of OGG1 ( ${ }^{\mathrm{Cys}} 326^{\mathrm{Cys}}$ ) and a $50 \%$ increase in vegetable and fruit intake are at $50 \%$ decreased risk of developing lung cancer. However, such a decrease in risk was not observed for the other genotypes (Sorensen et al. 2006). This study has therefore been undertaken in order to resolve the ambiguity regarding the association between OGG1 Ser326Cys polymorphism and susceptibility to upper aero-digestive tract and gastrointestinal cancers.

\section{Methods}

Literature search

Research articles relevant to the study were searched through the search engines "PubMed", "OMIM" and "Google Scholar" using search terms like "OGG1, hOGG1", "polymorphism, alleles, Ser326Cys, variants", "cancer, gastric cancer, colorectal cancer, head and neck cancer, oral cancer, aero-digestive tract cancer, pharyngeal cancer, pancreatic cancer, gallbladder cancer, cancer of digestive tract, esophageal cancer.

\section{Selection criteria}

Articles for the meta-analysis were selected if they met the following criteria: (1) Studies not prior to 2007 (2) case-control study related to the risk of OGG1 Ser326Cys polymorphism (3) articles written in English (4) studies in which full information about genotype distributions are reported (5) Studies in which genotype distribution of control populations are in accordance with Hardy-Weinberg Equilibrium ( $\mathrm{P}>0.05$ ) (6) only original research articles excluding reviews, letters and case reports. Studies prior to 2007 were excluded because they were mostly constrained to small study size.

\section{Data extraction}

All the data were extracted by two investigators (Das $S$ and Nath S) carefully and independently to maintain accuracy of the data, based on the inclusion criteria above. The information collected from each study are: author's name, year of publication, number of cases and controls, information of the genotypes of the cases and controls, ethnicity of the study population. The 
study populations were divided into Asians and Caucasians based on their ethnicity. Based on the location of cancer we have defined two cancer groups as UADT cancer (which includes cancer of head and neck, oral, pharynx and larynx) and GI cancer (which includes cancer of esophagus, pancreas, gallbladder, colon and rectum). In order to study the gene environment interaction, sub group analysis was performed with smoking habits between studies. The analysis was conducted on the basis of non-smokers versus smokers in the cancer patients.

\section{Statistical analysis}

Chi square test for Hardy-Weinberg equilibrium was performed in control populations. A P value greater than 0.05 was considered to be in accordance with HardyWeinberg equilibrium. Unconditional logistic regression was used to determine the odds ratio (OR) with $95 \%$ confidence interval for all the studies. Cochran's Q statistic (Cochran 1950) was used to find out heterogeneity across studies which was considered significant for $\mathrm{P}<0.05$. In the presence of significant heterogeneity the random effect model (DerSiminian and Laird method) (DerSimonian and Laird 1986) was used to calculate the pooled OR otherwise the fixed effect model (Mantel-Haenszel method) (Mantel and Haenszel 1959) was used. The Begg's funnel plot and Egger's test were used to determine publication bias (Stuck et al. 1998; Egger et al. 1997). All the analyses were performed using StatsDirect statistical software (Version 2.7.2).

\section{Results}

\section{Summary of included studies}

In a preliminary search, we identified 58 research articles related to OGG1 Ser326Cys polymorphism and the risk of head and neck, oral, pancreatic, gallbladder, colorectal and gastric cancers. Among all the articles identified, only 31 were subjected to further examination out of which only 17 (Kumar et al. 2011; Canbay et al. 2011; Srivastava et al. 2009; Gorgens et al. 2007; Laantri et al. 2011; Sameer et al. 2012; Sliwinski et al. 2011; Li et al. 2013; Upadhyay et al. 2010; Canbay et al. 2010; Palli et al. 2010; Engin et al. 2011; Curtin et al. 2009; Przybylowska et al. 2013; Pardini et al. 2008; Li et al. 2009; Srivastava et al. 2010) were found to meet the inclusion criteria (Table 1). Many of them were removed from the study due to lack of detailed information of all the genotypes and also due to non accordance of the controls with the Hardy-Weinberg equilibrium. The flowchart of the procedure for selecting the research articles for the study is described in Fig. 1.

\section{Meta-analysis result}

The meta-analysis suggests that there was significant risk for all the three models of OGG1 Ser326Cys polymorphism (for dominant model CG + GG vs CC; odds ratio, OR 1.22; $95 \%$ CI 1.05-1.41, recessive model GG vs CG + CC; OR 1.36; 95 \% CI 1.09-1.70, homozygote comparison GG vs CC; OR 1.46; 95 \% CI 1.12-1.92) (Fig. 2). Furthermore we have stratified the studies based on ethnicity to determine the role of OGG1 Ser326Cys polymorphism in the risk for cancer among different ethnic groups (Table 2).

The frequency of Ser/Cys and Cys/Cys genotype was slightly higher among cancer cases (0.37 and 0.06) than among the controls (0.35 and 0.05) for the Caucasian population. A similar trend was also observed in the Asian population where the frequency of Ser/Cys and Cys/Cys was higher among the cases $(0.43$ and 0.15$)$ than the controls (0.41 and 0.12). Results suggest that the polymorphism was a risk for cancer among both the Asian (CG + GG vs CC; OR 1.21; $95 \%$ CI 0.93-1.56, GG vs CG + CC; OR 1.40; 95 \% CI 1.09-1.80, GG vs CC; OR 1.56; 95 \% CI 1.15-2.11) and the Caucasian (CG + GG vs CC; OR 1.22; 95 \% CI 1.01-1.48, GG vs CG + CC; OR 1.29; 95 \% CI 0.95-1.76, GG vs CC; OR 1.40; 95 \% CI $0.97-2.03)$ populations for all the three models. Stratification on the basis of cancer types reveals that there was an elevated risk for individuals with this polymorphism for both the GI (CG + GG vs CC; OR 1.17; $95 \%$ CI $0.97-$ 1.40 , GG vs CG + CC; OR 1.28; 95 \% CI 0.95-1.74, GG vs CC; OR 1.36; 95 \% CI 0.96-1.92) and UADT (CG + GG vs CC; OR 1.32; $95 \%$ CI 1-1.74, GG vs CG + CC; OR 1.37; 95 \% CI 1.09-1.73, GG vs CC; OR 1.74; 95 \% CI 1.08-2.80) cancer (Fig. 3). However the risk for GI cancer was not significant.

\section{Smoking habit and OGG1 polymorphism}

Data pertaining to the habit of smoking was available only for a few of the included studies and the genotypes of OGG1 Ser326Cys stratified on the basis of smoking habit was also available only for cancer cases and not for the controls. We therefore conducted a metaanalysis with only 6 studies in order to determine the association of the polymorphism with the occurrence of GI and UADT cancers in patients who smoked compared to those who did not smoke. The interaction between OGG1 polymorphism and smoking habit was not found to increase the risk for cancer in all the three models (dominant CG + GG vs CC; OR 0.96; 95 \% CI 0.71-1.30, recessive GG vs CG + CC; OR 1.06; $95 \%$ CI 0.69-1.62, homozygote GG vs CC; OR 0.97; 95 \% CI $0.58-1.62)$. 
Table 1 Characteristics of the studies recruited for the meta-analysis

\begin{tabular}{|c|c|c|c|c|c|c|c|}
\hline Serial no. & Publications & $\begin{array}{l}\text { Number of con- } \\
\text { trols/cases }\end{array}$ & Cancer types & Country & Ethnicity & $\begin{array}{l}\text { Genotyping } \\
\text { method }\end{array}$ & Association/risk \\
\hline 1 & Kumar et al. (2011) & $278 / 278$ & Head and neck & India & Asian & PCR-RFLP & $\begin{array}{l}\text { High association/ } \\
\text { increased risk }\end{array}$ \\
\hline 2 & Sliwinski et al. (2011) & $280 / 265$ & Head and neck & Poland & Caucasian & PCR-RFLP & $\begin{array}{l}\text { High association/ } \\
\text { increased risk }\end{array}$ \\
\hline 3 & Gorgens et al. (2007) & $30 / 29$ & Oral & Germany & Caucasian & $\begin{array}{l}\text { PCR-Cycle sequenc- } \\
\text { ing }\end{array}$ & No association \\
\hline 4 & Li et al. (2013) & $300 / 231$ & Nasopharyngeal & China & Asian & PCR-CTPP & No association \\
\hline 5 & Laantri et al. (2011) & $506 / 541$ & Nasopharyngeal & North-African & Caucasian & TaqMan & No association \\
\hline 6 & $\begin{array}{l}\text { Upadhyay et al. } \\
\text { (2010) }\end{array}$ & $195 / 135$ & Esophageal & India & Asian & PCR-CTPP & No association \\
\hline 7 & Canbay et al. (2010) & $247 / 40$ & Gastric & Turkey & Caucasian & PCR-RFLP & No association \\
\hline 8 & Palli et al. (2010) & $545 / 304$ & Gastric & Italy & Caucasian & TaqMan & No association \\
\hline 9 & Engin et al. (2011) & $116 / 106$ & Gastric & Turkey & Caucasian & PCR-RFLP & No association \\
\hline 10 & Canbay et al. (2011) & $247 / 79$ & Colorectal & Turkey & Caucasian & PCR-RFLP & $\begin{array}{l}\text { High association/ } \\
\text { increased risk }\end{array}$ \\
\hline 11 & Curtin et al. (2009) & $1951 / 1582$ & Colorectal & USA & Caucasian & TaqMan & $\begin{array}{l}\text { Weak association } \\
\text { slightly increased } \\
\text { risk }\end{array}$ \\
\hline 12 & Sameer et al. (2012) & 200/114 & Colorectal & India & Asian & PCR-CTPP & No association \\
\hline 13 & $\begin{array}{l}\text { Przybylowska et al. } \\
\text { (2013) }\end{array}$ & $200 / 172$ & Colorectal & Poland & Caucasian & PCR-RFLP & $\begin{array}{l}\text { High association/ } \\
\text { increased risk }\end{array}$ \\
\hline 14 & Pardini et al. (2008) & $532 / 532$ & Colorectal & CzechRepublic & Caucasian & PCR-RFLP & $\begin{array}{l}\text { Weak association/ } \\
\text { slightly increased } \\
\text { risk }\end{array}$ \\
\hline 15 & Li et al. (2009) & $773 / 722$ & Pancreas & USA & Caucasian & TaqMan & $\begin{array}{l}\text { Weak association/ } \\
\text { increased risk }\end{array}$ \\
\hline 16 & $\begin{array}{l}\text { Srivastava et al. } \\
\text { (2009) }\end{array}$ & 204/173 & Gallbladder & India & Asian & PCR-RFLP & $\begin{array}{l}\text { High association/ } \\
\text { increased risk }\end{array}$ \\
\hline 17 & $\begin{array}{l}\text { Srivastava et al. } \\
\text { (2010) }\end{array}$ & $230 / 230$ & Gallbladder & India & Asian & PCR-RFLP & $\begin{array}{l}\text { High association/ } \\
\text { increased risk }\end{array}$ \\
\hline
\end{tabular}

\section{OGG1 polymorphism and risk of different types of cancer}

We observed that the cancers categorized in this study as GI and UADT cancers were of different types, viz. head and neck cancer, oral cancer, nasopharyngeal cancer, esophageal cancer, gastric cancer, colorectal cancer, pancreas cancer and gall bladder cancer (Table 3). Oral cancer, nasopharyngeal cancer and esophageal cancer are grouped together alongwith head and neck cancer (Barnes 2005). For head and neck cancer a very significantly increased risk was observed for all the three models (CG + GG vs CC; OR 1.3; 95 \% CI 0.99-1.73, GG vs CG + CC; OR 1.37; 95 \% CI 1.09-1.73, GG vs CC; OR $1.69 ; 95 \%$ CI 1.06-2.68). Similarly, increased risk was also observed for colorectal cancer for all the models (CG + GG vs CC; OR 1.29; 95 \% CI 0.9-1.84, GG vs CG + CC; OR 1.34; $95 \%$ CI 1.05-1.71, GG vs CC; OR 1.38; $95 \%$ CI 1.08-1.77). However, for gastric cancer we did not observe any risk for all the three models (CG + GG vs CC; OR 0.9; 95 \% CI 0.71-1.14, GG vs CG + CC; OR 0.78; 95 \% CI 0.47-1.29, GG vs CC; OR 0.76 ; $95 \%$ CI $0.45-1.27$ ). Meta-analysis could not be performed for pancreas cancer and gall bladder cancer due to less number of studies meeting the selection criteria $(<3)$.

\section{Heterogeneity test}

In this study significant heterogeneity was observed for all the models of OGG1 Ser326Cys polymorphism $\left(\mathrm{CG}+\mathrm{GG}\right.$ vs CC; $\mathrm{P}<0.0001, I^{2}=69.1 \%$, GG vs $\mathrm{CG}+\mathrm{CC} ; \mathrm{P}=0.0248, I^{2}=44.4 \%, \mathrm{CC}$ vs GG; P $=0.0019$, 


\section{8 relevant citations identified and examined methodically}

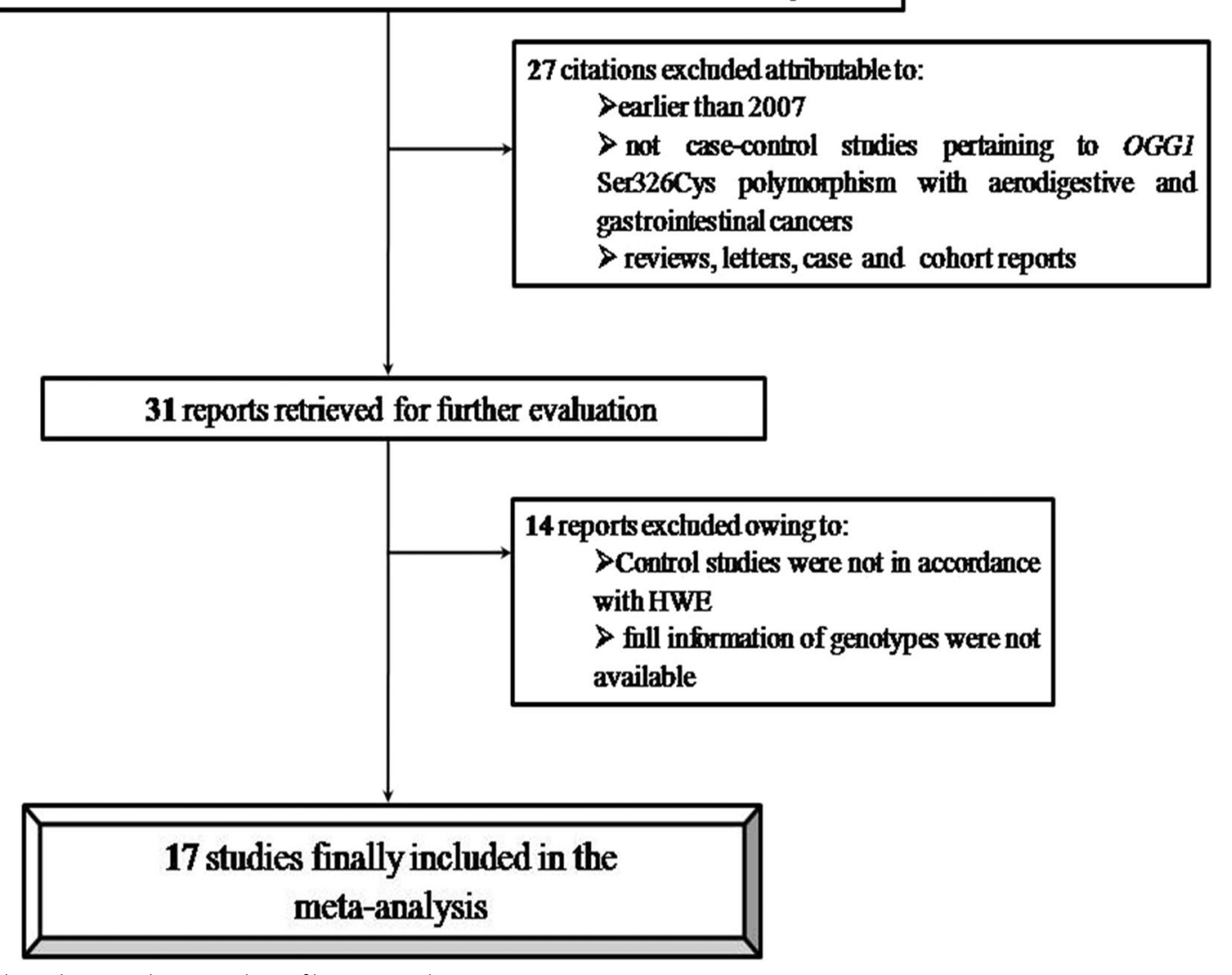

Fig. 1 Flow chart showing the procedure of literature selection

$\left.I^{2}=57.1 \%\right)$ and subsequently the random effect model was selected. We then tried to assess the source of heterogeneity based on ethnicity (Asian and Caucasian), sample size $(<500$ subjects and $\geq 500$ subjects $)$ and cancer types (GI cancer and UADT cancer). From the analysis it was found that subsequent heterogeneity was contributed by Caucasian population $\left(I^{2}=74.3 \%\right)$ and sample size of below $500\left(I^{2}=72.6 \%\right)$ among the studies. While in case of cancer types heterogeneity was found to be contributed by both the GI $\left(I^{2}=70.3 \%\right)$ and UADT $\left(I^{2}=64.9 \%\right)$ cancers.

\section{Publication bias and sensitivity test}

Begg's funnel plot (Fig. 4) and Egger's test were used to determine publication bias. We did not find any asymmetry in the funnel plot indicating no publication bias. The result was validated by the Egger's test for all the models $(p>0.05)$. Sensitivity test was performed in order to find out the effect of individual study on the pooled odds ratio. From the sensitivity test it was observed that no individual study was found to significantly impact on the overall result.

\section{Discussion}

DNA repair genes play an important role in maintaining the genomic integrity of a cell. Polymorphisms in these genes may alter the protein function and thus hamper the DNA repair capacity of an individual (Goode et al. 2002). The OGG1gene encodes the enzyme required for removal of the 8-oxoG adduct from DNA. Although many polymorphisms have been reported in OGG1, the C/G polymorphism at the 326 codon of exon 7 which results in an amino acid substitution from serine to cysteine is of great importance 


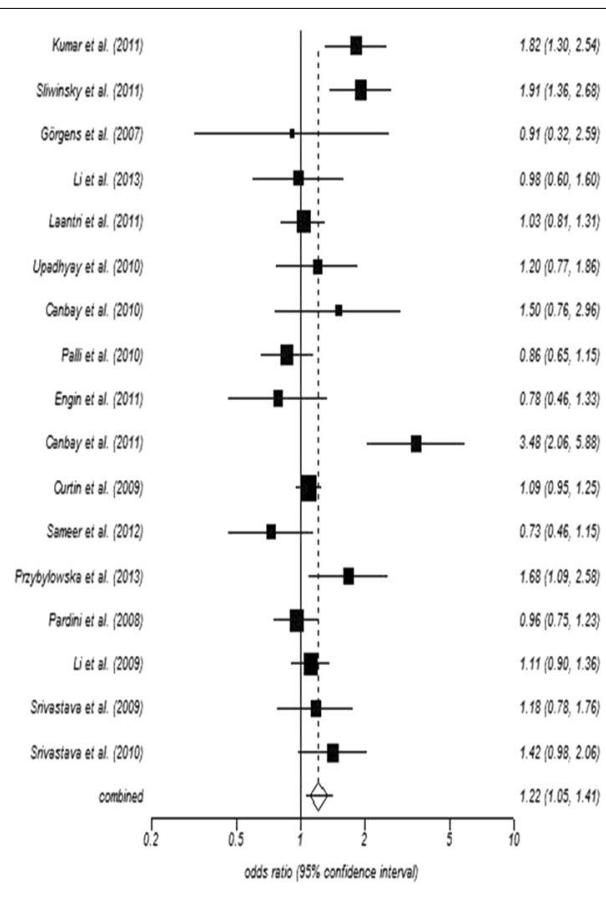

a

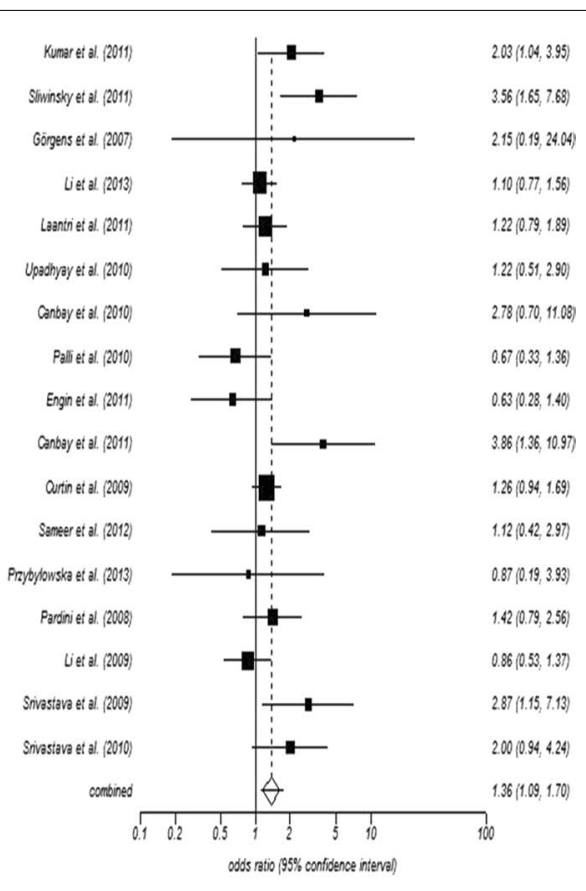

b

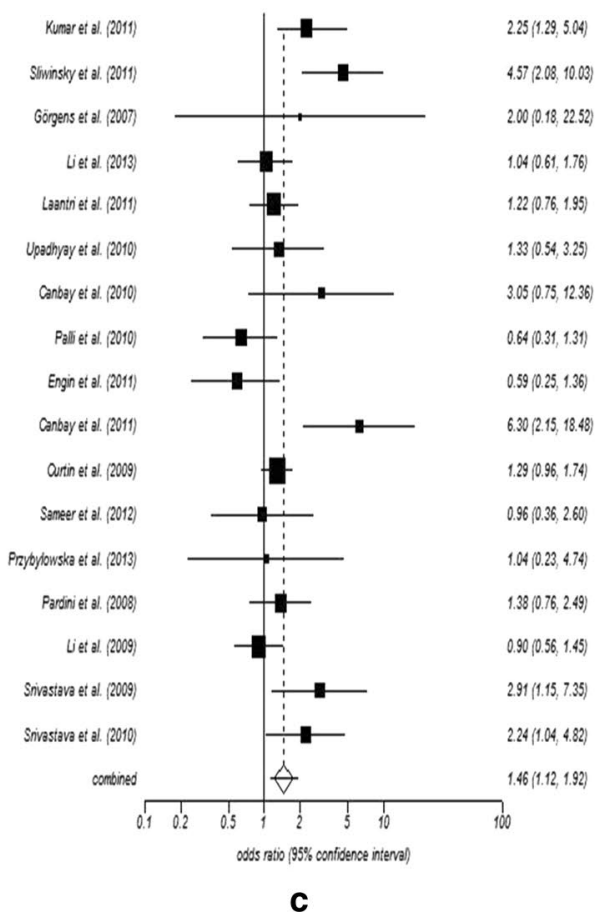

Fig. 2 Figure showing forest plots of OGG1 Ser326Cys polymorphism in association with upper aero-digestive tract cancer and gastro-intestinal cancer for all the three models: a dominant model, CG + GG versus CC, b recessive model, CG + CC versus GG, c homozygous model, GG versus CC 
Table 2 Pooled OR of the OGG1 Ser326Cys polymorphism based on ethnicity, sample size and cancer type

\begin{tabular}{|c|c|c|c|c|c|c|c|c|}
\hline \multirow[t]{2}{*}{ Variables } & \multirow[t]{2}{*}{ No. of studies } & \multirow[t]{2}{*}{ Case/control } & \multicolumn{2}{|c|}{ Dominant model } & \multicolumn{2}{|l|}{ Recessive model } & \multicolumn{2}{|c|}{ Homozygous model } \\
\hline & & & OR (95 \% Cl) & $P^{a}$ & OR (95 \% Cl) & $\mathrm{P}^{\mathrm{a}}$ & OR (95 \% Cl) & $\mathrm{P}^{\mathrm{a}}$ \\
\hline \multicolumn{9}{|l|}{ Ethnicity } \\
\hline Asian & 6 & $1161 / 1407$ & $1.21(0.93-1.56)$ & 0.15 & $1.40(1.09-1.80)$ & $0.009^{*}$ & $1.56(1.15-2.11)$ & $0.004^{*}$ \\
\hline Caucasian & 11 & $4372 / 5427$ & $1.22(1.01-1.48)$ & $0.03^{*}$ & $1.29(0.95-1.76)$ & 0.104 & $1.40(0.97-2.03)$ & 0.07 \\
\hline \multicolumn{9}{|l|}{ Sample size } \\
\hline$<500$ & 8 & $943 / 1474$ & $1.31(0.93-1.85)$ & 0.122 & $1.64(1.14-2.35)$ & $0.007^{*}$ & $1.83(1.01-3.29)$ & $0.044^{*}$ \\
\hline$\geq 500$ & 9 & $4590 / 5360$ & $1.16(0.99-1.35)$ & 0.06 & $1.23(1.05-1.44)$ & $0.012^{*}$ & $1.32(0.99-1.76)$ & 0.06 \\
\hline \multicolumn{9}{|l|}{ Cancer type } \\
\hline $\mathrm{Gl}$ & 11 & $4054 / 5245$ & $1.17(0.97-1.40)$ & 0.09 & $1.28(0.95-1.74)$ & 0.103 & $1.36(0.96-1.92)$ & 0.08 \\
\hline UADT & 6 & $1479 / 1589$ & $1.32(1-1.74)$ & $<0.05^{*}$ & $1.37(1.09-1.73)$ & $<0.05^{*}$ & $1.74(1.08-2.80)$ & $0.02^{*}$ \\
\hline
\end{tabular}

a $\mathrm{P}$ heterogeneity

* Significant at $\mathrm{P}<0.05$

as it has been linked to the increased risk for different cancers. In few studies, the OGG1 protein encoded by the $326^{\text {Ser }}$ variant is found to have more DNA repair activity than that coded by the $326^{\mathrm{Cys}}$ variant indicating the role of this polymorphism in carcinogenesis (Elahi et al. 2002). Previous studies including several metaanalyses pertaining to the role of OGG1 Ser326Cys polymorphism with the risk for different cancers were found to be ambiguous. Hence, several meta-analyses were also performed in recent years in order to address this ambiguity. Meta-analyses by Yan et al. (2014), Zhang et al. (2011) and Wang et al. (2011) did not find any association between OGG1 polymorphism and the risk for pancreatic cancer, colorectal cancer and gastric cancer respectively. However, another study by Su et al. (2014) reported that the OGG1 polymorphism was significantly associated with increased risk for colorectal cancer in Caucasian population. Similar risk was also found for esophageal cancer in a study by Wang et al. (2013). Thus, the variations in the results among different studies still persisted. In an effort to resolve this ambiguity, we have performed a meta-analysis to determine the role of OGG1 Ser326Cys polymorphism on the risk for UADT cancer and GI cancer which includes different independent case control studies on head and neck cancer, gastric cancer, colorectal cancer, pancreatic cancer, gallbladder cancer and esophageal cancer. Our study has revealed a significant association of OGG1 polymorphism with UADT and GI cancer risk. For all the three models (CG + GG vs CC, GG vs $C G+C C$ and $G G$ vs $C C$ ) we observe a significant risk, clearly indicating the role of the mutant $\mathrm{G}$ allele in increasing the risk for UADT and GI cancers.
Stratified analysis based on ethnicity reveals that the OGG1 polymorphism increases the risk for cancer in both Asian and Caucasian populations. The maximum risk for Asian population was observed for GG vs CC genotype with a 1.56 fold increase in risk. Similar trend was also observed for the Caucasian population with a 1.4 fold increase in risk. We also observed a significant increase in risk by 1.4 fold among Asians with GG vs CG + CC genotype. The 17 articles included in this study were found to have been performed on either Asian or Caucasian populations. Hence, this meta-analysis reports findings pertaining to only these two ethnicities, although the ethnicity was not a pre-determined criterion for selection.

Environmental factors such as smoking in association with different polymorphisms were found to play an important role in the onset of various cancers (Das et al. 2015). However, our study revealed no association between the habit of smoking and OGG1 Ser326Cys polymorphism. This may be due to a decrease in sample size resulting from stratification of data based on smoking habit. Our study based on the risk for different types of cancers and OGG1 polymorphism showed highly significant risk for both the head and neck and colorectal cancers which was in accordance with Su et al. (2014) and Wang et al. (2013) respectively. However, no risk was observed for gastric cancer. On further stratifying our study into GI and UADT cancers it was observed that individuals with $G$ allele are at an increased risk for both the type of cancer. For both GI and UADT cancers the maximum risk was observed for the homozygote model with a 1.36 and 1.74 folds increase in risk respectively. 


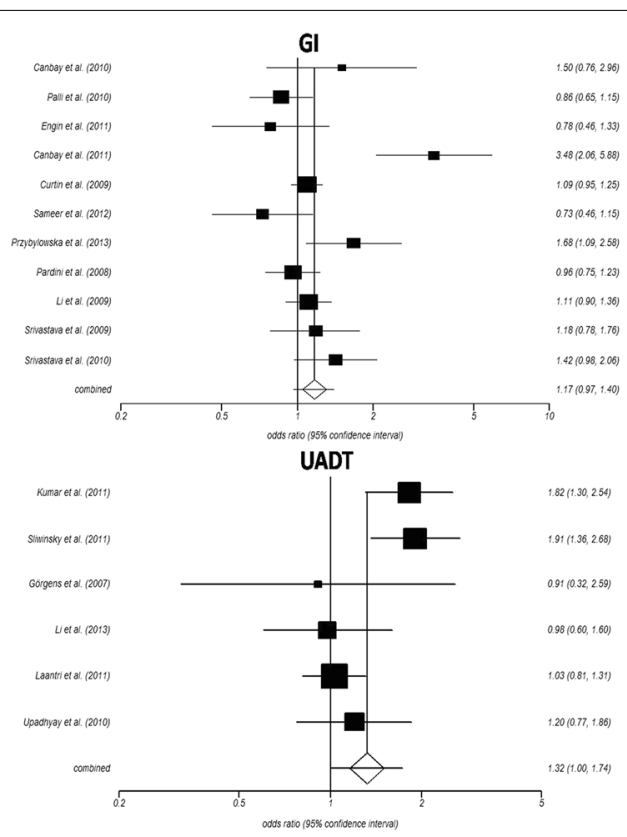

a
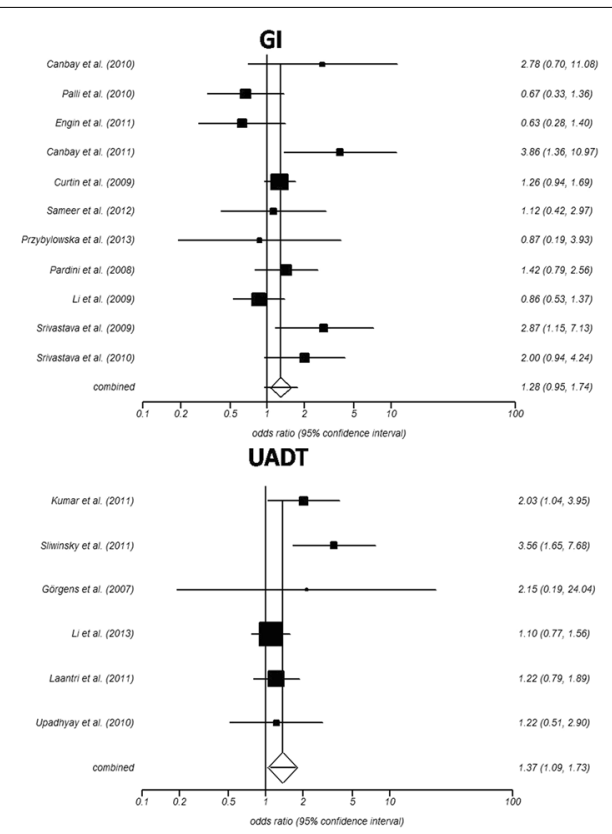

b
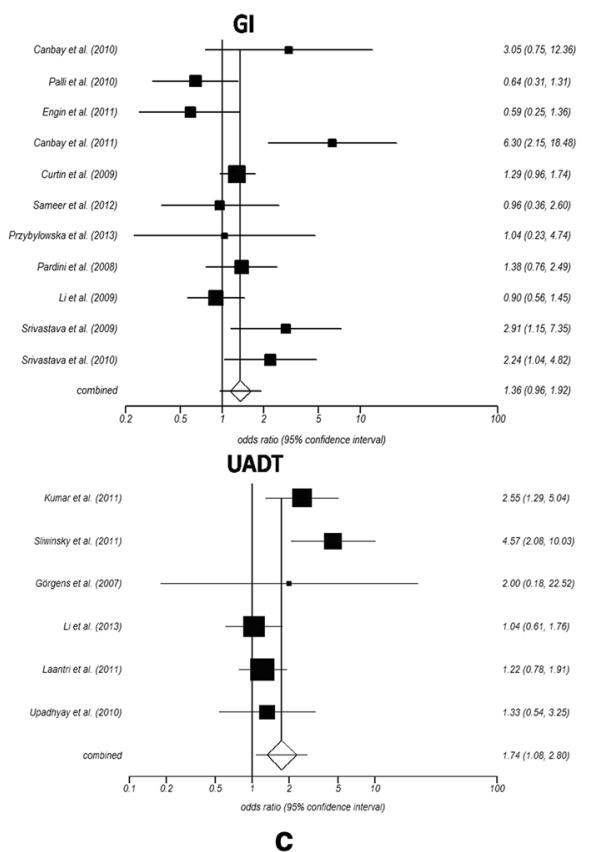

Fig. 3 Figure showing forest plot of stratified analysis based on cancer types i.e. gastro-intestinal (GI) and upper aero-digestive tract (UADT) cancer in association with OGG1 Ser326Cys polymorphism for all the three models: a dominant model, CG + GG versus CC, b recessive model, CG + CC versus $\mathrm{GG}$, c homozygous model, $\mathrm{GG}$ versus $\mathrm{CC}$

Heterogeneity testing revealed significant heterogeneity among all the three models in our study. However, while trying to assess the source of heterogeneity, we found that maximum heterogeneity was contributed by Caucasian population, indicating a presence of ethnicity specific effect of OGG1 on the risk for UADT and GI cancers. Significant heterogeneity was also contributed by sample size and cancer types which indicate that the study recruited for the meta-analysis might have contributed to the increased heterogeneity for which the random effect model was used for calculating the pooled OR. Besides that we have also calculated publication bias 
Table 3 Pooled OR of the OGG1 Ser326Cys polymorphism based on different types of cancer

\begin{tabular}{|c|c|c|c|c|c|c|c|c|}
\hline \multirow[t]{2}{*}{ Type of cancer } & \multirow[t]{2}{*}{ No. of studies } & \multirow[t]{2}{*}{ Case/Control } & \multicolumn{2}{|c|}{ Dominant model } & \multicolumn{2}{|c|}{ Recessive model } & \multicolumn{2}{|c|}{ Homozygous model } \\
\hline & & & OR (95 \% Cl) & $\mathbf{P}^{a}$ & OR (95 \% Cl) & $P^{a}$ & OR (95 \% Cl) & $P^{a}$ \\
\hline Head and neck & 6 & $1479 / 1589$ & $1.3(0.99-1.73)$ & $<0.05^{*}$ & $1.37(1.09-1.73)$ & $0.007^{*}$ & $1.69(1.06-2.68)$ & $0.02^{*}$ \\
\hline Gastric & 3 & $450 / 908$ & $0.9(0.71-1.14)$ & 0.39 & $0.78(0.47-1.29)$ & 0.34 & $0.76(0.45-1.27)$ & 0.3 \\
\hline Colorectal & 5 & 2479/3130 & $1.29(0.9-1.84)$ & 0.15 & $1.34(1.05-1.71)$ & $0.01^{*}$ & $1.38(1.08-1.77)$ & $0.009^{*}$ \\
\hline
\end{tabular}

a P heterogeneity

* Significant at $\mathrm{P}<0.05$

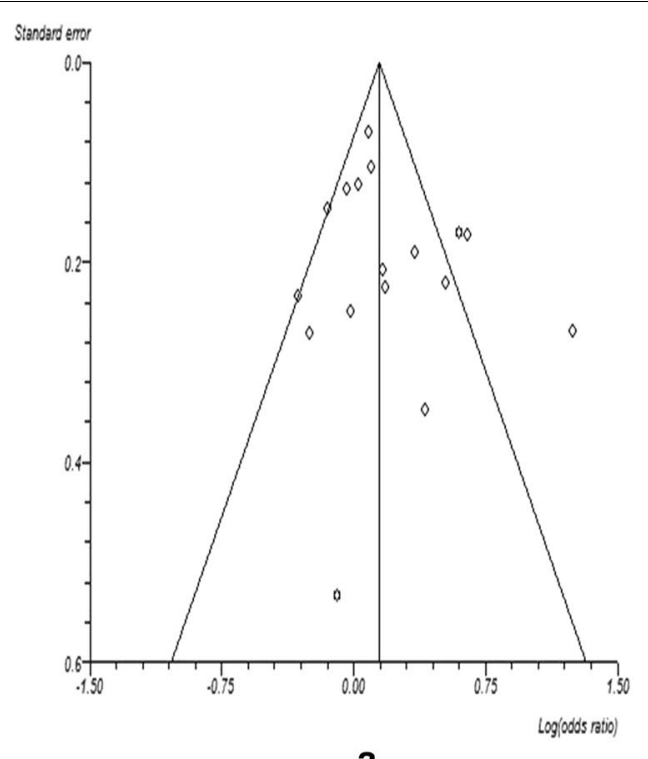

a

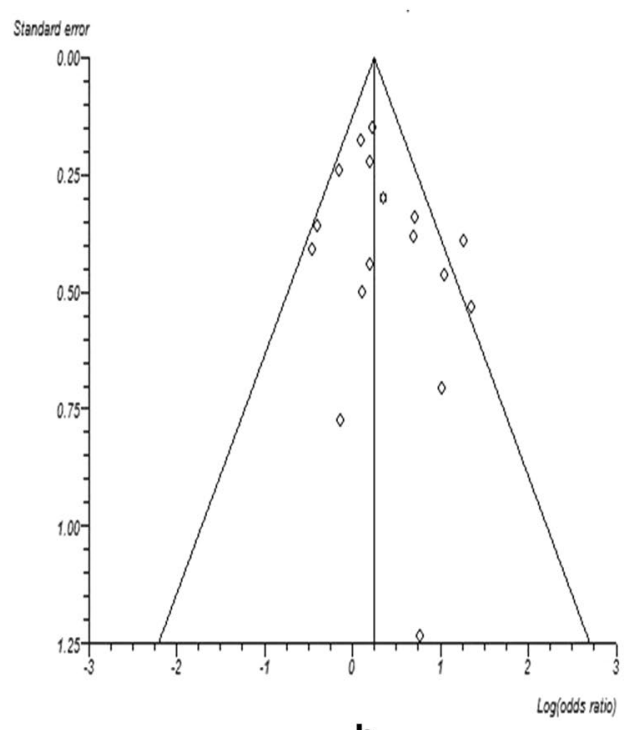

b

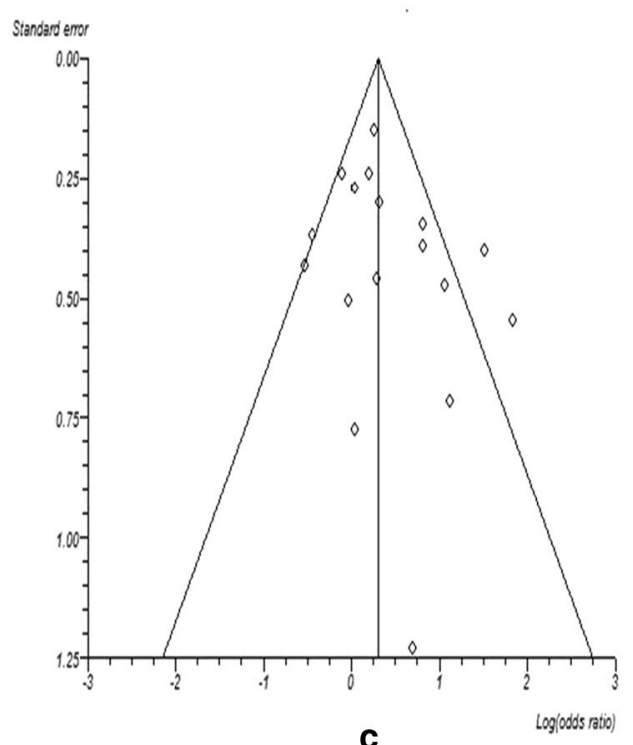

Fig. 4 Figure showing funnel plot for publication bias a dominant model, CG + GG versus CC, b recessive model, CG + CC versus GG, c homozygous model, GG versus CC 
by Begg's funnel plot and Egger's test, the results of which indicated no such bias in our study. This authenticates that our meta-analysis results are relatively stable.

Although we have conducted our meta-analysis with a very large number of cases and controls the study has some limitations. Firstly, most of the study groups were of Caucasian origin and only few studies pertaining to the Asian population could be recruited for the study. Secondly, we were not able to conduct our study for the other ethnicities, which should be researched in future studies; and thirdly, only a few studies recruited for the meta-analysis contained detailed information on the smoking habits of cancer patients and controls, as a result of which the analysis based on smoking habit must be further validated on a larger study group.

In conclusion, our meta-analysis provides evidence that the OGG1 Ser326Cys polymorphism may be associated with an increased risk for UADT and GI cancers in both Asian and Caucasian populations.

\section{Authors' contributions}

SD and SN collated research articles, analysed the data and wrote the manuscript; $A B$ analysed data and wrote the manuscript; SKG and YC designed the study and wrote the manuscript. All authors read and approved the final manuscript.

\section{Acknowledgements}

This work was funded by Grant with sanction no. BT/CP/09/NE/TBP/2010 dated 20th OCTOBER, 2011, from Department of Biotechnology, Government of India to Yashmin Choudhury and Sankar Kumar Ghosh. Sambuddha Das, Sayantan Nath and Aditi Bhowmik were supported by University Grants Commission-Basic Scientific Research fellowship.

\section{Competing interests}

The authors declare that they have no competing interests.

Received: 12 September 2015 Accepted: 16 February 2016

Published online: 29 February 2016

\section{References}

Babron MC, Kazma R, Gaborieau V, McKay J, Brennan P, Sarasin A, Benhamou S (2014) Genetic variants in DNA repair pathways and risk of upper aerodigestive tract cancers: combined analysis of data from two genome-wide association studies in European populations. Carcinogenesis 35(7):15231527. doi:10.1093/carcin/bgu075

Barnes L (2005) Pathology and genetics of head and neck tumours, vol 9. IARC, Lyon

Bhatt AN, Mathur R, Farooque A, Verma A, Dwarakanath BS (2010) Cancer biomarkers_current perspectives. Indian J Med Res 132:129-149

Bhowmik A, Das S, Bhattacharjee A, Choudhury B, Naiding M, Deka S, Ghosh SK, Choudhury Y (2015) MDM2 and TP53 polymorphisms as predictive markers for head and neck cancer in Northeast Indian population: effect of gene-gene and gene-environment interactions. Asian Pac J Cancer Prev 16(14):5767-5772

Bravard A, Vacher M, Moritz E, Vaslin L, Hall J, Epe B, Radicella JP (2009) Oxidation status of human OGG1-S326C polymorphic variant determines celIular DNA repair capacity. Cancer Res 69(8):3642-3649. doi:10.1158/00085472.CAN-08-3943

Canbay E, Agachan B, Gulluoglu M, Isbir T, Balik E, Yamaner S, Bulut T, Cacina C, Eraltan IY, Yilmaz A, Bugra D (2010) Possible associations of APE1 polymorphism with susceptibility and HOGG1 polymorphism with prognosis in gastric cancer. Anticancer Res 30(4):1359-1364
Canbay E, Cakmakoglu B, Zeybek U, Sozen S, Cacina C, Gulluoglu M, Balik E, Bulut T, Yamaner S, Bugra D (2011) Association of APE1 and hOGG1 polymorphisms with colorectal cancer risk in a Turkish population. Curr Med Res Opin 27(7):1295-1302. doi:10.1185/03007995.2011.573544

Cochran WG (1950) The comparison of percentages in matched samples. Biometrika 37(3-4):256-266

Curtin K, Samowitz WS, Wolff RK, Ulrich CM, Caan BJ, Potter JD, Slattery ML (2009) Assessing tumor mutations to gain insight into base excision repair sequence polymorphisms and smoking in colon cancer. Cancer Epidemiol Biomark Prev 18(12):3384-3388. doi:10.1158/1055-9965. EPI-09-0955

Das S, Bhowmik A, Bhattacharjee A, Choudhury B, Naiding M, Laskar AK, Ghosh SK, Choudhury Y (2015) XPD, APE1, and MUTYH polymorphisms increase head and neck cancer risk: effect of gene-gene and gene-environment interactions. Tumour Biol. doi:10.1007/s13277-015-3472-5

DerSimonian R, Laird N (1986) Meta-analysis in clinical trials. Control Clin Trials 7(3):177-188. doi:10.1016/0197-2456(86)90046-2

Egger M, Davey Smith G, Schneider M, Minder C (1997) Bias in meta-analysis detected by a simple, graphical test. BMJ 315(7109):629-634

Elahi A, Zheng Z, Park J, Eyring K, McCaffrey T, Lazarus P (2002) The human OGG1 DNA repair enzyme and its association with orolaryngeal cancer risk. Carcinogenesis 23(7):1229-1234

Engin AB, Karahalil B, Engin A, Karakaya AE (2011) DNA repair enzyme polymorphisms and oxidative stress in a Turkish population with gastric carcinoma. Mol Biol Rep 38(8):5379-5386. doi:10.1007/s11033-011-0690-9

Goode EL, Ulrich CM, Potter JD (2002) Polymorphisms in DNA repair genes and associations with cancer risk. Cancer Epidemiol Biomark Prev 11(12):1513-1530

Gorgens H, Muller A, Kruger S, Kuhlisch E, Konig IR, Ziegler A, Schackert HK, Eckelt U (2007) Analysis of the base excision repair genes MTH1, OGG1 and MUTYH in patients with squamous oral carcinomas. Oral Oncol 43(8):791-795. doi:10.1016/j.oraloncology.2006.10.004

Hoeijmakers JH (2009) DNA damage, aging, and cancer. N Engl J Med 361(15):1475-1485. doi:10.1056/NEJMra0804615

Kumar A, Pant MC, Singh HS, Khandelwal S (2011) Role of OGG1 Ser326Cys polymorphism and 8-oxoguanine DNA damage in risk assessment of squamous cell carcinoma of head and neck in North Indian population. Mutat Res 726(2):227-233. doi:10.1016/j.mrgentox.2011.09.015

Laantri N, Jalbout M, Khyatti M, Ayoub WB, Dahmoul S, Ayad M, Bedadra W, Abdoun M, Mesli S, Kandil M, Hamdi-Cherif M, Boualga K, Bouaouina N, Chouchane L, Benider A, Ben-Ayed F, Goldgar D, Corbex M (2011) XRCC1 and hOGG1 genes and risk of nasopharyngeal carcinoma in North African countries. Mol Carcinog 50(9):732-737. doi:10.1002/mc.20754

Li D, Suzuki H, Liu B, Morris J, Liu J, Okazaki T, Li Y, Chang P, Abbruzzese JL (2009) DNA repair gene polymorphisms and risk of pancreatic cancer. Clin Cancer Res 15(2):740-746. doi:10.1158/1078-0432.CCR-08-1607

Li Q, Wang JM, Peng Y, Zhang SH, Ren T, Luo H, Cheng Y, Wang D (2013) Association of DNA base-excision repair XRCC1, OGG1 and APE1 gene polymorphisms with nasopharyngeal carcinoma susceptibility in a Chinese population. Asian Pac J Cancer Prev 14(9):5145-5151

Mantel N, Haenszel W (1959) Statistical aspects of the analysis of data from retrospective studies of disease. J Natl Cancer Inst 22(4):719-748

Palli D, Polidoro S, D'Errico M, Saieva C, Guarrera S, Calcagnile AS, Sera F, Allione A, Gemma S, Zanna I, Filomena A, Testai E, Caini S, Moretti R, GomezMiguel MJ, Nesi G, Luzzi I, Ottini L, Masala G, Matullo G, Dogliotti E (2010) Polymorphic DNA repair and metabolic genes: a multigenic study on gastric cancer. Mutagenesis 25(6):569-575

Pardini B, Naccarati A, Novotny J, Smerhovsky Z, Vodickova L, Polakova V, Hanova M, Slyskova J, Tulupova E, Kumar R, Bortlik M, Barale R, Hemminki K, Vodicka P (2008) DNA repair genetic polymorphisms and risk of colorectal cancer in the Czech Republic. Mutat Res 638(1-2):146-153. doi:10.1016/j.mrfmmm.2007.09.008

Pourhoseingholi MA, Vahedi M, Baghestani AR (2015) Burden of gastrointestinal cancer in Asia; an overview. Gastroenterol Hepatol Bed Bench 8(1):19-27

Przybylowska K, Kabzinski J, Sygut A, Dziki L, Dziki A, Majsterek I (2013) An association selected polymorphisms of XRCC1, OGG1 and MUTYH gene and the level of efficiency oxidative DNA damage repair with a risk of colorectal cancer. Mutat Res 745-746:6-15. doi:10.1016/j. mrfmmm.2013.04.002 
Sameer AS, Nissar S, Abdullah S, Chowdri NA, Siddiqi MA (2012) DNA repair gene 8-oxoguanine DNA glycosylase Ser326Cys polymorphism and colorectal cancer risk in a Kashmiri population. DNA Cell Biol 31(4):541-546. doi:10.1089/dna.2011.1349

Sawyers C (2004) Targeted cancer therapy. Nature 432(7015):294-297. doi:10.1038/nature03095

Sedelnikova OA, Redon CE, Dickey JS, Nakamura AJ, Georgakilas AG, Bonner WM (2010) Role of oxidatively induced DNA lesions in human pathogenesis. Mutat Res 704(1-3):152-159. doi:10.1016/j.mrrev.2009.12.005

Sliwinski T, Przybylowska K, Markiewicz L, Rusin P, Pietruszewska W, ZelinskaBlizniewska H, Olszewski J, Morawiec-Sztandera A, Mlynarski W, Majsterek I (2011) MUTYH Tyr165Cys, OGG1 Ser326Cys and XPD Lys751GIn polymorphisms and head neck cancer susceptibility: a case control study. Mol Biol Rep 38(2):1251-1261. doi:10.1007/s11033-010-0224-x

Sorensen M, Raaschou-Nielsen O, Hansen RD, Tjonneland A, Overvad K, Vogel $U$ (2006) Interactions between the OGG1 Ser326Cys polymorphism and intake of fruit and vegetables in relation to lung cancer. Free Radic Res 40(8):885-891. doi:10.1080/10715760600733129

Srivastava A, Srivastava K, Pandey SN, Choudhuri G, Mittal B (2009) Singlenucleotide polymorphisms of DNA repair genes OGG1 and XRCC1: association with gallbladder cancer in North Indian population. Ann Surg Oncol 16(6):1695-1703. doi:10.1245/s10434-009-0354-3

Srivastava K, Srivastava A, Mittal B (2010) Polymorphisms in ERCC2, MSH2, and OGG1 DNA repair genes and gallbladder cancer risk in a population of Northern India. Cancer 116(13):3160-3169. doi:10.1002/cncr.25063

Stuck AE, Rubenstein LZ, Wieland D (1998) Bias in meta-analysis detected by a simple, graphical test. Asymmetry detected in funnel plot was probably due to true heterogeneity. BMJ 316(7129):469 (author reply 470-461)
Su Y, Xu A, Zhu J (2014) The effect of oxoguanine glycosylase 1 rs1052133 polymorphism on colorectal cancer risk in Caucasian population. Tumour Biol 35(1):513-517. doi:10.1007/s13277-013-1072-9

Upadhyay R, Malik MA, Zargar SA, Mittal B (2010) OGG1 Ser326Cys polymorphism and susceptibility to esophageal cancer in low and high at-risk populations of northern India. J Gastrointest Cancer 41(2):110-115. doi:10.1007/s12029-009-9124-5

Wang Z, Hu J, Cai W, Zhong J (2011) Lack of association between the 8-oxoguanine DNA glycosylase gene Ser326Cys polymorphism and gastric cancer: evidence from a meta-analysis. Asian Pac J Cancer Prev 12(12):3427-3431

Wang Z, Gan L, Nie W, Geng Y (2013) The OGG1 Ser326Cys polymorphism and the risk of esophageal cancer: a meta-analysis. Genet Test Mol Biomark 17(10):780-785. doi:10.1089/gtmb.2013.0224

Yan Y, Chen X, Li T, Li M, Liang H (2014) Association of OGG1 Ser326Cys polymorphism and pancreatic cancer susceptibility: evidence from a metaanalysis. Tumour Biol 35(3):2397-2402. doi:10.1007/s13277-013-1317-7

Zhang Y, He BS, Pan YQ, Xu YQ, Wang SK (2011) Association of OGG1 Ser326Cys polymorphism with colorectal cancer risk: a meta-analysis. Int J Colorectal Dis 26(12):1525-1530. doi:10.1007/s00384-011-1258-9

Zhou PT, Li B, Ji J, Wang MM, Gao CF (2015) A systematic review and metaanalysis of the association between OGG1 Ser326Cys polymorphism and cancers. Med Oncol 32(2):472. doi:10.1007/s12032-014-0472-z

\section{Submit your manuscript to a SpringerOpen ${ }^{\circ}$ journal and benefit from:}

- Convenient online submission

- Rigorous peer review

- Immediate publication on acceptance

- Open access: articles freely available online

- High visibility within the field

- Retaining the copyright to your article

Submit your next manuscript at $\boldsymbol{s p r i n g e r o p e n . c o m ~}$ 